\title{
Pengaruh Variasi Kendaraan Leader Dan Panjang Platoon Terhadap Kecepatan
}

\author{
Sri Ramayanti ${ }^{1}$, Bayu Martanto Adji ${ }^{2}$, Yosritzal $^{3}$ \\ Fakultas Teknik, Universitas Andalas ${ }^{1,2,3}$ \\ Email: sri.ramayanti.st@gmail.com¹, bayu@eng.unand.ac.id ${ }^{2}$,Yosritzal@gmail.com³ \\ DOI: http://dx.doi.org/10.31869/rtj.v5i1.2734
}

\begin{abstract}
Naiknya jumlah kepemilikan kendaraan akan berpengaruh pada peningkatan arus lalu lintas, yang biasanya akan menghasilkan kemacetan di jaringan jalan. Fenomena ini mengakibatkan kendaraan cenderung berjalan beriring - iringan (platoon). Beberapa karakteristik yang dipakai dalam mendeskripsikan fenomena platoon tersebut yaitu: jarak antar kendaran (headway) kecepatan rata-rata dan jumlah kendaraan dalam platoon. Penelitian ini untuk menganalisa pengaruh variasi kendaraan leader dan panjang platoon terhadap kecepatan kendaraan. Penelitian dilakukan pada jalan raya Padang - Bukittinggi yang merupakan jalan arteri di Propinsi Sumatera Barat. Data yang dipakai adalah data primer, survey langsung dilapangan dengan merekam arus lalu lintas kendaraan beriringan (traffic platoon) selama 2 hari. Untuk menentukan kecepatan diambil jarak $50 \mathrm{~m}$ dan waktu diukur dengan stop program. Nilai rata - rata headway relatif sama pada pengukuran pada saat jam sibuk dan jam tidak sibuk. Secara umum headway antar kendaraan bervariasi, disebabkan kecepatan kendaraan yang tidak konstan. Pengukuran platoon sampai dengan 2 detik lebih berpengaruh terhadap penurunan kecepatan daripada pengukuran platoon sampai dengan 3 detik. Pada pengukuran platoon sampai dengan 2 detik terjadi penurunan rerata kecepatan sebesar $8.36 \%$ setiap penambahan 1 ( satu) kendaraan pada platoon, sedangkan pada pengukuran platoon sampai dengan 3 detik terjadi penurunan rerata kecepatan sebesar $4.40 \%$.
\end{abstract}

Keywords: platoon, headway, rerata kecepatan, kendaraan leader

\section{PENDAHULUAN}

Menurut data Kepolisian Republik Indonesia tahun 2017, rata - rata 3 orang meninggal setiap jam akibat kecelakaan lalu lintas. Besarnya jumlah kecelakaan tersebut disebabkan oleh beberapa faktor, yaitu : $61 \%$ kecelakaan disebabkan oleh faktor manusia yaitu terkait dengan kemampuan serta karakter pengemudi, kemudian $30 \%$ disebabkan oleh faktor prasarana dan lingkungan dan $9 \%$ disebabkan oleh faktor kendaraan.

Dengan naiknya jumlah kepemilikan kendaraan akan mempengaruhi peningkatan arus lalu lintas, yang biasanya akan menghasilkan kemacetan dijaringan jalan, akibatnya kendaraan cenderung untuk bergerak beriring - iringan (platoon). Pada periode 2014 - 2018 terdapat peningkatan jumlah kendaraan bermotor yang cukup signifikan yaitu 6.49 \%pertahun. Peningkatan terjadi pada semua jenis kendaraan, yang paling tinggi yaitu terjadi pada mobil penumpang $6.88 \%$ pertahun, kemudian diikuti oleh sepeda motor, mobil barang dan bus masing - masing sebesar $6.61 \%$ pertahun, $5.68 \%$ pertahun dan $1.42 \%$ pertahun. Menurut Mathew et al. (2013) menjelaskan karakteristik yang dipakai dalam mendeskripsikan fenomena platoon tersebut yaitu : jarak antar kendaran (headway) kecepatan rata-rata dan jumlah kendaraan dalam platoon.

Jarak antar kendaran (Nilai Headway) dipergunakan sebagai kontrol jarak aman antara kendaraan yang sedang beriringan untuk menghindari terjadinya tabrakan belakang, karena pengemudi membutuhkan waktu dan ruang untuk bereaksi melakukan pengereman yang aman.

Menurut MKJI (1997), pada jalan luar kota kendaraan dibagi menjadi 5 tipe, yaitu kendaraan Ringan (Light Vechicles = LV), Kendaraan Berat Menengah ( MediumHeavy Vechicles $=$ MHV), Truk Besar $($ Large Truck $=$ LT), Bis Besar ( Large Bus= LB), Sepeda motor (Motor Cycle $=\mathrm{MC}$ ).

Kendaraan tak bermotor tidak dianggap sebagai bagian dari arus lalu lintas. Yang termasuk dalam kendaraan tak bermotor yatu kendaraan beroda dengan orang atau hewan sebagai tenaga penggerak, meliputi : becak, sepeda,kereta kuda dan dorong.

Menurut Khisty (2005) kecepatan didefinisikan sebagai laju perjalanan. Kecepatan dinyatakan dalam kilometer per $\mathrm{jam}(\mathrm{km} / \mathrm{jam})$. 
Menurut MKJI (1997) Iringan(Peleton) adalah kondisi lalu lintas bila kendaraan bergerak dalam antrian (peleton) dengan kecepatan yang sama karena tertahan oleh kendaraan yang didepan (pimpinan peleton), catatan waktu antara ke depan $\leq 5$ detik.

Purnawan, Adilla (2013) ada 4 tipe iringan kendaraan (platoon), yaitu : LV - LV, $\mathrm{LV}$ - HV, HV - HV, HV - LV, dimana LV(Light Vehicle) kendaraan ringan dan HV(Heavy Vehicle) kendaraan berat, bus termasuk kedalam kendaraan berat dan angkot termasuk kendaraan ringan. Tipe platoon yang paling tinggi adalah LV - LV, dengan nilai headway pada interval $1,1-1,8$ detik, nilai ini relatif sama untuk survey pada 3 jam puncak, pagi, siang dan sore.

Raja S et al. (2014) menyatakan bahwa terdapat hubungan antara leader platoon dengan kecepatan dan ukuran platoon berdasarkan berat total kendaraan (Gross vehicle Weight,GVW). Penelitian ini menunjukkan bahwa kecepatan platoon berkurang seiring dengan meningkatnya GVW pemimpin platoon. Namun terbukti bahwa ukuran platoon rata rata yang dipimpin oleh kendaraan berat lebih kecil dari platoon yang dipimpin oleh kendaraan ringan. Perhitungan platoon dilakukan pada headway sampai dengan 4 detik.

Tujuan penelitian ini untuk mengetahui pengaruh variasi kendaraan leader dan panjang platoon terhadap kecepatan kendaraan dalam platoon.Manfaat penelitian ini adalah sebagai pedoman atau acuan untuk pihak terkait untuk mempertimbangkan karakteristik platoon dalam perencanaan jalan raya dan manajemen lalu lintas.

\section{METODE PENELITIAN}

Secara umum program kerja penelitian dapat dilihat pada bagan alir seperti gambar.1 berikut :

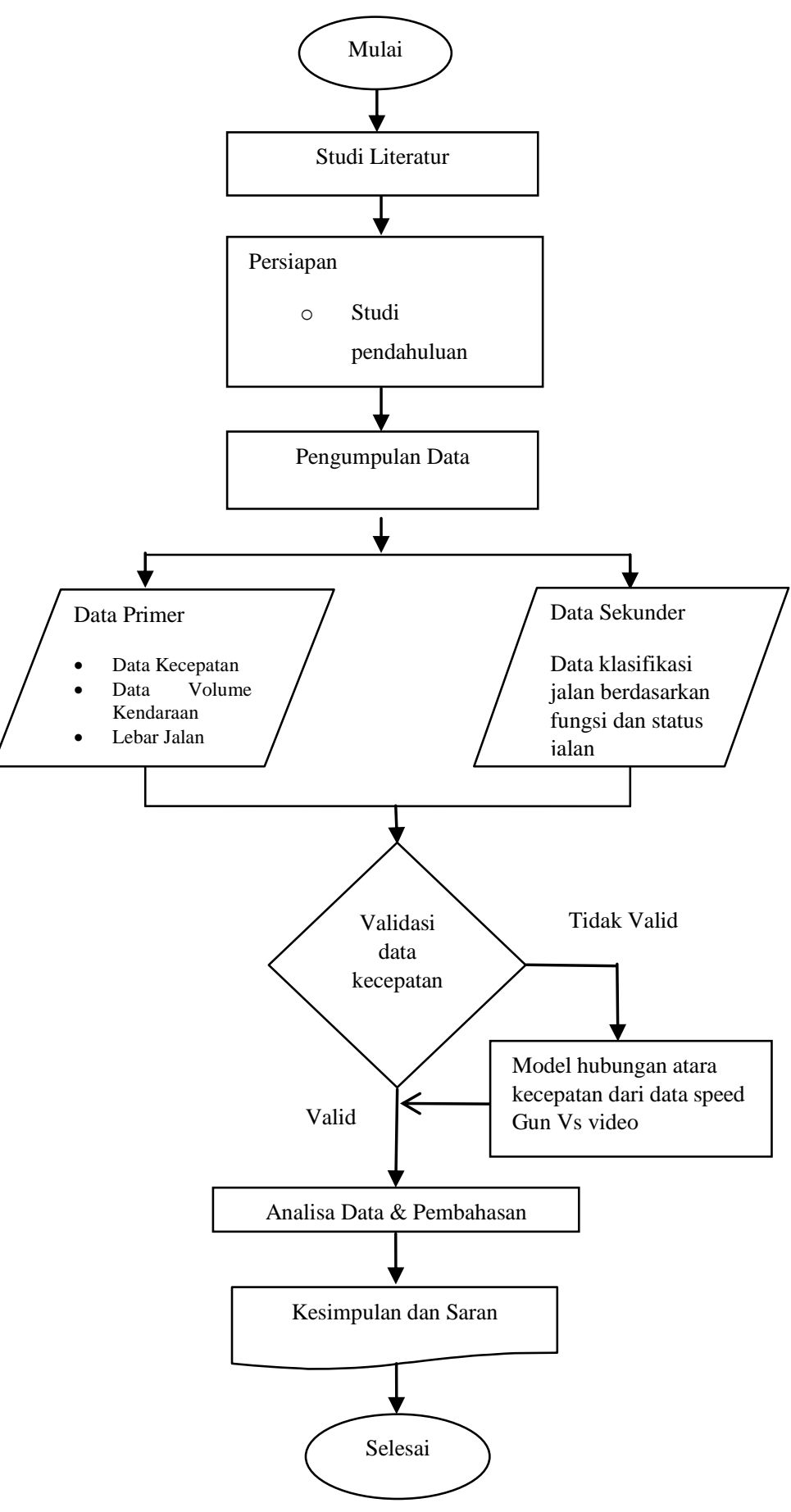

Gambar.1 Diagram alir penelitian

Secara umum penelitian dimulai dengan studi pendahuluan yaitu dengan mempelajari secara mendalam tentang kecepatan dan headway kendaraan beriringan (platoon), kemudian dilakukan pemilihan lokasi dan dilakukan persiapan peralatan survey, yaitu handycam, memory card, tripod, paying, stopwatch dan meteran. Survey dilakukan selama 2 hari dengan merekam kondisi lalu lintas menggunakan handycam. Kemudian dikumpulkan data primer berupa data 
kecepatan, data volume kendaraan dan lebar jalan, sedangkan untuk data sekunder yaitu berupa data klasifikasi jalan berdasarkan fungsi dan status jalan. Kemudian dilakukan validasi data kecepatan dengan membandingkan pengukuran kecepatan dengan handycam dengan pengukuran dengan alat speed gun. Data - data hasil survey kemudian ditampilkan dalam bentuk tabel dan diagram serta dianalisa secara statistik dengan bantuan microsoft excel.

\section{HASIL DAN PEMBAHASAN}

Dari pengumpulan data sekunder, yaitu klasifikasi jalan berdasarkan fungsi dan status, berdasarkan KepMen PUPR Nomor : 248/KPTS/M/2015 tentang Penetapan ruas jalan dalam jaringan jalan primer menurut fungsinya sebagai jalan arteri (JAP) dan jalan kolektor -1 (JKP-1), maka data jalan yang disurvey adalah sebagai berikut :

Status jalan : Jalan Nasional

Nama ruas : : Lubuk Alung - Simp.

Duku

No. Ruas : : 026

Panjang ruas : $\quad 13,49 \mathrm{Km}$

Fungsi : Jalan Arteri (JAP)

Hasil pengamatan yang didapat setelah melakukan survey selama 2 hari yaitu : 1 (satu) hari pada hari libur yang dilakukan pada hari Minggu tanggal 25 Agustus 2019 dan 1 (satu) hari pada hari kerja yang dilakukan pada hari Selasa tanggal 27 Agustus 2019, didapat data lebar jalan adalah 6.5 meter dengan lebar bahu jalan 2.8 meter, volume kendaraan, pola platoon, headway dan kecepatan kendaraan dalam platoon.

\section{Volume Kendaraan}

Untuk kendaraan yang disurvey adalah : kendaraan ringan (LV), kendaraan berat menengah (MHV), bus besar (LB), truk besar (LT), dan sepeda motor (MC).

Pada survey hari kerja dilakukan selama 8 jam 30 menit yaitu dari pukul 07.00 WIB sampai pukul 12.30 WIB dan pukul 13.15 sampai pukul 16.15 WIB. Pada survey hari libur dilakukan selama 5 (lima) jam yaitu dari pukul 16.00 WIB sampai pukul 21.00 WIB. Pengamatan dilakukan untuk 2 (dua) arah, yaitu dari arah Padang menuju Bukittinggi dan dari arah Bukittinggi menuju Padang.

Data rekapitulasi volume kendaraan dapat dilihat pada tabel 1
Tabel 1 Rekapitulasi volume kendaraan

\begin{tabular}{|c|c|c|c|c|c|c|}
\hline \multirow{2}{*}{$\begin{array}{l}\text { Hari- } \\
\text { arah }\end{array}$} & \multicolumn{5}{|c|}{ Jenis Kendaraan } & \multirow{2}{*}{$\begin{array}{c}\text { total } \\
\text { (smp } \\
\text { ) }\end{array}$} \\
\hline & LV & $\begin{array}{c}\text { MH } \\
\text { V }\end{array}$ & $\begin{array}{l}\mathrm{L} \\
\mathrm{B}\end{array}$ & $\begin{array}{l}\mathrm{L} \\
\mathrm{T}\end{array}$ & $\mathrm{MC}$ & \\
\hline \multicolumn{7}{|l|}{ Selasa } \\
\hline $\begin{array}{l}\text { Padang } \\
- \\
\text { Bukittin } \\
\text { ggi }\end{array}$ & $\begin{array}{c}323 \\
0\end{array}$ & $\begin{array}{c}117 \\
7\end{array}$ & 14 & $\begin{array}{c}17 \\
6\end{array}$ & $\begin{array}{c}477 \\
4\end{array}$ & $\begin{array}{c}9578 \\
.6\end{array}$ \\
\hline $\begin{array}{l}\text { Bukittin } \\
\text { ggi - } \\
\text { Padang }\end{array}$ & $\begin{array}{c}295 \\
9\end{array}$ & $\begin{array}{c}117 \\
1\end{array}$ & 19 & $\begin{array}{c}13 \\
2\end{array}$ & $\begin{array}{c}438 \\
1\end{array}$ & $\begin{array}{c}9400 \\
.3\end{array}$ \\
\hline Minggu & & & & & & \\
\hline $\begin{array}{l}\text { Padang } \\
- \\
\text { Bukittin } \\
\text { ggi }\end{array}$ & $\begin{array}{c}298 \\
7\end{array}$ & 406 & 17 & $\begin{array}{c}11 \\
0\end{array}$ & $\begin{array}{c}262 \\
9\end{array}$ & $\begin{array}{c}5765 \\
.7\end{array}$ \\
\hline $\begin{array}{l}\text { Bukittin } \\
\text { ggi - } \\
\text { Padang }\end{array}$ & $\begin{array}{c}321 \\
9\end{array}$ & 383 & 17 & 45 & $\begin{array}{c}394 \\
3\end{array}$ & $\begin{array}{c}6693 \\
.3\end{array}$ \\
\hline
\end{tabular}

Penentuan jam sibuk dan jam tidak sibuk

Penentuan jam sibuk dan tidak sibuk untuk masing - masing hari dan berdasarkan arah, dapat dilihat pada tabel 2

Tabel 2 Rekapitulasi waktu jam sibuk dan tidak sibuk

\begin{tabular}{|l|c|c|l|}
\hline \multicolumn{1}{|c|}{ Hari } & Jam & $\begin{array}{c}\text { Volume } \\
\text { Lalu } \\
\text { lintas } \\
\text { (smp/jam })\end{array}$ & Keterangan \\
\hline Selasa & & & \\
\hline $\begin{array}{l}\text { Padang- } \\
\text { Bukittinggi }\end{array}$ & $\begin{array}{c}09.45- \\
10.45\end{array}$ & 1248,9 & Sibuk \\
\hline & $\begin{array}{c}07.45- \\
08.45\end{array}$ & 1003,6 & $\begin{array}{l}\text { Tidak } \\
\text { Sibuk }\end{array}$ \\
\hline $\begin{array}{l}\text { Bukittinggi } \\
\text { - Padang }\end{array}$ & $\begin{array}{c}14.30- \\
15.30\end{array}$ & 1335,4 & Sibuk \\
\hline & $07.15-$ & 1032,3 & Tidak \\
& 08.15 & & Sibuk \\
\hline Minggu & & & \\
\hline Padang- \\
Bukittinggi & $\begin{array}{c}16.15- \\
17.15\end{array}$ & 1359,8 & Sibuk \\
\hline & $\begin{array}{c}19.00- \\
20.00\end{array}$ & 1019,4 & $\begin{array}{l}\text { Tidak } \\
\text { Sibuk }\end{array}$ \\
\hline Bukittinggi & $19.00-$ & 1479,9 & Sibuk \\
- Padang & 20.00 & & \\
\hline & $18.00-$ & 1199,4 & $\begin{array}{l}\text { Tidak } \\
\text { Sibuk }\end{array}$ \\
\hline
\end{tabular}

Rekapitulasi Nilai Headway

Berdasarkan perhitungan headway untuk masing - masing hari berdasarkan arah 
pergerakan kendaraan pada jam sibuk dan jam tidak sibuk, rata - rata nilai headway dapat dilihat pada tabel 3

Tabel 3 Rekapitulasi rata - rata nilai headway

\begin{tabular}{|l|c|c|}
\hline \multicolumn{1}{|c|}{ Hari - Arah } & $\begin{array}{c}\text { headway } \\
\text { sampai } \\
\text { dengan 2 } \\
\text { detik } \\
\text { (detik) }\end{array}$ & $\begin{array}{c}\text { headway } \\
\text { sampai } \\
\text { dengan 3 } \\
\text { detik } \\
\text { (detik) }\end{array}$ \\
\hline Selasa & 1.37 & 1.67 \\
\hline $\begin{array}{l}\text { Padang - Bukittinggi, } \\
\text { JamSibuk }\end{array}$ & 1.25 & 1.67 \\
\hline $\begin{array}{l}\text { Padang - Bukittinggi, Jam } \\
\text { Tidak Sibuk }\end{array}$ & 1.39 & 1.67 \\
\hline $\begin{array}{l}\text { Bukittinggi - Padang, Jam } \\
\text { Sibuk }\end{array}$ & 1.25 & 1.66 \\
\hline $\begin{array}{l}\text { Bukittinggi - Padang, Jam } \\
\text { Tidak sibuk }\end{array}$ & $\mathbf{1 . 3 2}$ & $\mathbf{1 . 6 7}$ \\
\hline Rata - rata & 1.45 & 1.80 \\
\hline Minggu & 1.46 & 2.00 \\
\hline $\begin{array}{l}\text { Padang - Bukittinggi, } \\
\text { JamSibuk }\end{array}$ & $\mathbf{1 . 4 7}$ & $\mathbf{1 . 8 7}$ \\
\hline $\begin{array}{l}\text { Padang - Bukittinggi, Jam } \\
\text { Tidak Sibuk }\end{array}$ & 1.84 \\
\hline $\begin{array}{l}\text { Bukittinggi - Padang, Jam } \\
\text { Sibuk }\end{array}$ & 1.40 & \\
\hline $\begin{array}{l}\text { Bukittinggi - Padang, Jam } \\
\text { Tidak sibuk }\end{array}$ & 1.45 & \\
\hline Rata - rata & 1.83 \\
\hline
\end{tabular}

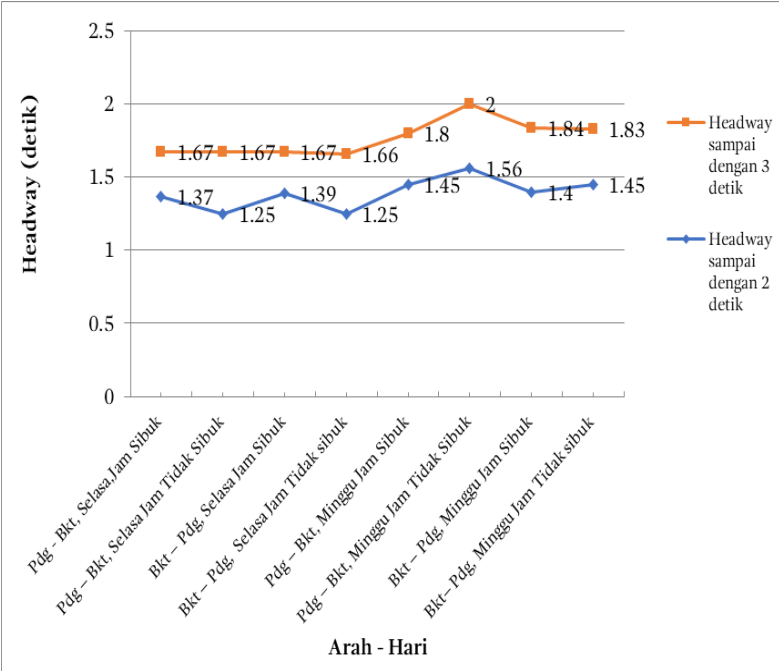

Gambar 2 headway rata - rata

Gambar 2 menampilkan perbandingan nilai rata - rata headway sampai dengan 2 detik dan nilai rata - rata headway sampai dengan 3 detik, terlihat bahwa rata - rata headway 3 detik lebih tinggi dari pada headway 2 detik.
Dari grafik dapat dilihat bahwa tidak ada pengaruh signifikan pengukuran yang dilakukan pada jam sibuk dan jam tidak sibuk terhadap nilai headway.

\section{Rekapitulasi Jenis Kendaraan Pemimpin Platoon (Kendaraan Leader)}

Tabel 4 Rekapitulasi jenis kendaraan pemimpin platoon pada pengukuran platoon dengan headway sampai dengan 3 detik

\begin{tabular}{|l|r|r|r|r|r|}
\hline \multicolumn{1}{|c|}{ Hari - Arah } & LV & $\begin{array}{c}\text { M } \\
\text { HV }\end{array}$ & $\begin{array}{c}\text { L } \\
\text { B }\end{array}$ & $\begin{array}{c}\text { L } \\
\text { T }\end{array}$ & $\begin{array}{r}\text { tot } \\
\text { al }\end{array}$ \\
\hline Selasa & & & & & \\
\hline $\begin{array}{l}\text { Padang - } \\
\text { Bukittinggi Sibuk }\end{array}$ & 67 & 52 & - & 9 & 12 \\
\hline $\begin{array}{l}\text { Padang - } \\
\text { Bukittinggi Tidak } \\
\text { Sibuk }\end{array}$ & 62 & 29 & - & 5 & 96 \\
\hline $\begin{array}{l}\text { Bukittinggi - } \\
\text { Padang Sibuk }\end{array}$ & 82 & 54 & - & 3 & 13 \\
\hline $\begin{array}{l}\text { Bukittinggi - } \\
\text { Padang Tidak } \\
\text { Sibuk }\end{array}$ & 35 & 61 & - & 6 & 10 \\
\hline Minggu & & & & & 2 \\
\hline $\begin{array}{l}\text { Padang - } \\
\text { Bukittinggi Sibuk }\end{array}$ & 117 & 27 & 1 & 9 & 15 \\
\hline $\begin{array}{l}\text { Padang - } \\
\text { Bukittinggi Tidak } \\
\text { Sibuk }\end{array}$ & 92 & 12 & - & 1 & 11 \\
\hline $\begin{array}{l}\text { Bukittinggi - } \\
\text { Padang Sibuk }\end{array}$ & 140 & 28 & 3 & 6 & 17 \\
\hline $\begin{array}{l}\text { Bukittinggi - } \\
\text { Padang Tidak } \\
\text { Sibuk }\end{array}$ & 117 & 22 & - & 4 & 14 \\
\hline Total & 712 & 285 & 4 & 5 & 10 \\
\hline & & & & & \\
\hline
\end{tabular}

Tabel 5 Rekapitulasi jenis kendaraan pemimpin platoon pada pengukuran platoon dengan headway sampai dengan 2 detik

\begin{tabular}{|l|r|r|r|r|r|}
\hline Hari - Arah & LV & $\begin{array}{c}\text { MH } \\
\text { V }\end{array}$ & $\begin{array}{c}\text { L } \\
\text { B }\end{array}$ & $\begin{array}{c}\text { L } \\
\text { T }\end{array}$ & total \\
\hline Selasa & & & & & \\
\hline $\begin{array}{l}\text { Padang - Bukittinggi } \\
\text { Sibuk }\end{array}$ & 77 & 58 & - & 5 & 140 \\
\hline $\begin{array}{l}\text { Padang - Bukittinggi } \\
\text { Tidak Sibuk }\end{array}$ & 54 & 21 & - & 7 & 82 \\
\hline $\begin{array}{l}\text { Bukittinggi - Padang } \\
\text { Sibuk }\end{array}$ & 94 & 43 & - & 4 & 141 \\
\hline $\begin{array}{l}\text { Bukittinggi - Padang } \\
\text { Tidak Sibuk }\end{array}$ & 38 & 57 & - & 6 & 101 \\
\hline
\end{tabular}


Vol. 5 No.1 Januari 2022

http://jurnal.umsb.ac.id/index.php/RANGTEKNIKJOURNAL

\begin{tabular}{|c|c|c|c|c|c|c|c|c|c|c|}
\hline Minggu & & & & & Tidak Sibuk & & & & & \\
\hline Padang - & 129 & 33 & 2 & 5 & 169 Minggu & & & & & \\
\hline Sibu & & & & & Padang - & 47. & 46. & 42. & 41. & 42. \\
\hline Sukittinggi & 80 & 8 & - & 4 & 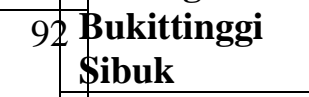 & 57 & 12 & 62 & 86 & 40 \\
\hline $\begin{array}{l}\text { Bukittinggi - Padang } \\
\text { Sibuk }\end{array}$ & 149 & 17 & 1 & 3 & $\begin{array}{l}170 \text { Padang - } \\
\text { Bukittinggi }\end{array}$ & $\begin{array}{r}59 . \\
28\end{array}$ & $\begin{array}{r}57 . \\
79\end{array}$ & $\begin{array}{r}57 . \\
77\end{array}$ & $\begin{array}{r}56 . \\
54\end{array}$ & $\begin{array}{r}52 . \\
98\end{array}$ \\
\hline Bukittinggi - Padang & 117 & 17 & - & 3 & 137 Tidak Sibuk & & & & & \\
\hline Tidak & & & & & Bukittinggi - & 61. & 59. & 56. & 54. & 48. \\
\hline Total & 738 & 254 & 3 & 37 & $\begin{array}{c}895 \text { Padang } \\
\text { Sibuk }\end{array}$ & 35 & 11 & 81 & 27 & 81 \\
\hline \multirow{2}{*}{\multicolumn{5}{|c|}{$\begin{array}{l}\text { Tabel } 4 \text { menampilkan rekapitulasi jenis } \\
\text { kendaraan pemimpin platoon untuk platoon } \\
\text { dengan headway sampai dengan } 3 \text { detik, } \\
\text { terdapat } 1054 \text { platoon yang terbentuk selama } \\
\text { jam pengamatan dan jenis kendaraan }\end{array}$}} & $\begin{array}{l}\text { Bukittinggi - } \\
\text { Padang } \\
\text { Tidak Sibuk }\end{array}$ & $\begin{array}{r}64 . \\
06\end{array}$ & $\begin{array}{r}57 . \\
55\end{array}$ & $\begin{array}{r}57 . \\
01\end{array}$ & $\begin{array}{r}55 . \\
60\end{array}$ & $\begin{array}{r}55 . \\
76\end{array}$ \\
\hline & & & & & Rat & $\begin{array}{r}57 . \\
56\end{array}$ & $\begin{array}{r}54 . \\
63 \\
\end{array}$ & $\begin{array}{r}52 . \\
09\end{array}$ & $\begin{array}{l}51 . \\
77\end{array}$ & $\begin{array}{r}46 . \\
57\end{array}$ \\
\hline
\end{tabular}
pemimpin platoon terbanyak yaitu kendaraan ringan (LV). Diikuti oleh kendaraan berat menengah (MHV) dan truk besar(MHV), hanya 4 platoon yang dipimpin oleh bis besar (LB).

Tabel 5 menampilkan rekapitulasi jenis kendaraan pemimpin platoon untuk platoon dengan headway sampai dengan 2 detik, terdapat 895 platoon yang terbentuk selama jam pengamatan dan jenis kendaraan pemimpin platoon terbanyak yaitu kendaraan ringan (LV). Diikuti oleh kendaraan berat menengah (MHV) dan truk besar(MHV), hanya 3 platoon yang dipimpin oleh bis besar (LB).

\section{Rekapitulasi Distribusi Kecepatan berdasarkan Ukuran Platoon \\ Tabel 6 Rekapitulasi kecepatan rata - rata kendaraan berdasarkan ukuran platoon pada pengukuran headway sampai dengan 3 detik}

\begin{tabular}{|c|c|c|c|c|c|}
\hline \multirow[t]{2}{*}{ Hari - Arah } & \multicolumn{5}{|c|}{$\begin{array}{c}\text { Kecepatan rata - rata } \\
(\mathrm{Km} / \mathrm{jam})\end{array}$} \\
\hline & 2 & 3 & 4 & 5 & 6 \\
\hline \multicolumn{6}{|l|}{ Selasa } \\
\hline $\begin{array}{l}\text { Padang - } \\
\text { Bukittinggi } \\
\text { Sibuk }\end{array}$ & $\begin{array}{r}58 . \\
47\end{array}$ & $\begin{array}{r}54 . \\
70\end{array}$ & $\begin{array}{r}53 . \\
93\end{array}$ & $\begin{array}{l}51 . \\
37\end{array}$ & $\begin{array}{r}52 . \\
20\end{array}$ \\
\hline $\begin{array}{l}\text { Padang - } \\
\text { Bukittinggi } \\
\text { Tidak Sibuk }\end{array}$ & $\begin{array}{r}54 . \\
40\end{array}$ & $\begin{array}{r}53 . \\
13\end{array}$ & $\begin{array}{r}47 . \\
77\end{array}$ & $\begin{array}{r}55 . \\
42\end{array}$ & $\begin{array}{r}39 . \\
00\end{array}$ \\
\hline $\begin{array}{l}\text { Bukittinggi - } \\
\text { Padang } \\
\text { Sibuk }\end{array}$ & $\begin{array}{r}53 . \\
76\end{array}$ & $\begin{array}{r}48 . \\
55\end{array}$ & $\begin{array}{r}42 . \\
87\end{array}$ & $\begin{array}{r}41 . \\
15\end{array}$ & $\begin{array}{r}39 . \\
69\end{array}$ \\
\hline $\begin{array}{l}\text { Bukittinggi - } \\
\text { Padang }\end{array}$ & $\begin{array}{r}61 . \\
57\end{array}$ & $\begin{array}{r}60 . \\
07\end{array}$ & $\begin{array}{r}57 . \\
97\end{array}$ & $\begin{array}{r}57 . \\
94\end{array}$ & $\begin{array}{r}41 . \\
73 \\
\end{array}$ \\
\hline
\end{tabular}

Tabel 6 menampilkan rekapitulasi kecepatan rata - rata kendaraan berdasarkan ukuran platoon pada pengukuran platoon dengan headway sampai dengan 3 detik. Dari tabel dapat dilihat kecepatan rata rata platoon ukuran 2 adalah $57.56 \mathrm{~km} / \mathrm{jam}$, ukuran 3 adalah $54.63 \mathrm{~km} / \mathrm{jam}$. Ukuran 4 adalah 52.09 $\mathrm{km} / \mathrm{jam}$ ukuran 5 adalah $51.77 \mathrm{~km} / \mathrm{jam}$ dan ukuran 6 adalah $46.57 \mathrm{~km} / \mathrm{jam}$. Semakin besar ukuran platoon semakin menurun kecepatan rata - rata kendaraannya.

Tabel 7 menampilkan rekapitulasi kecepatan rata - rata kendaraan berdasarkan ukuran platoon pada pengukuran platoon dengan headway sampai dengan 2 detik. Dari tabel dapat dilihat kecepatan rata rata platoon ukuran 2 adalah $57.94 \mathrm{~km} / \mathrm{jam}$, ukuran 3 adalah $54.25 \mathrm{~km} / \mathrm{jam}$. Ukuran 4 adalah 50.47 $\mathrm{km} / \mathrm{jam}$ ukuran 5 adalah $46.26 \mathrm{~km} / \mathrm{jam}$ dan ukuran 6 adalah $40.40 \mathrm{~km} / \mathrm{jam}$. Semakin besar ukuran platoon semakin menurun kecepatan rata - rata kendaraannya.

Tabel 7 Rekapitulasi kecepatan rata - rata kendaraan berdasarkan ukuran platoon pada pengukuran headway sampai dengan 2 detik

\begin{tabular}{|l|r|r|r|r|r|}
\hline \multirow{2}{*}{ Hari - Arah } & \multicolumn{5}{|c|}{ Kecepatan rata - rata (Km/jam) } \\
\cline { 2 - 6 } & 2 & 3 & 4 & 5 & 6 \\
\hline Selasa & & & & & \\
\hline Padang - & 60.3 & 57.4 & 54.3 & 53. & 52. \\
Bukittinggi & 6 & 2 & 4 & 27 & 69 \\
Sibuk & & & & & \\
\hline Padang- & 50.8 & 49.1 & 44.8 & 48. & - \\
Bukittinggi & 3 & 8 & 5 & 98 & \\
Tidak Sibuk & & & & & \\
\hline Bukittinggi - & 50.9 & 50.1 & 41.3 & 36. & 34. \\
\hline
\end{tabular}


Vol. 5 No.1 Januari 2022

http://jurnal.umsb.ac.id/index.php/RANGTEKNIKJOURNAL

\begin{tabular}{|c|c|c|c|c|c|}
\hline $\begin{array}{l}\text { Padang } \\
\text { Sibuk }\end{array}$ & 1 & 2 & 3 & 41 & 24 \\
\hline $\begin{array}{l}\text { Bukittinggi - } \\
\text { Padang } \\
\text { Tidak Sibuk }\end{array}$ & $\begin{array}{r}58.2 \\
8\end{array}$ & $\begin{array}{r}57.7 \\
5\end{array}$ & $\begin{array}{r}56.5 \\
2\end{array}$ & $\begin{array}{r}52 . \\
10\end{array}$ & $\begin{array}{r}25 . \\
90\end{array}$ \\
\hline \multicolumn{6}{|l|}{ Minggu } \\
\hline $\begin{array}{l}\text { Padang - } \\
\text { Bukittinggi } \\
\text { Sibuk }\end{array}$ & $\begin{array}{r}49.0 \\
0\end{array}$ & $\begin{array}{r}46.1 \\
3\end{array}$ & $\begin{array}{r}43.6 \\
1\end{array}$ & $\begin{array}{r}39 . \\
89\end{array}$ & $\begin{array}{r}38 . \\
26\end{array}$ \\
\hline $\begin{array}{l}\text { Padang - } \\
\text { Bukittinggi } \\
\text { Tidak Sibuk }\end{array}$ & $\begin{array}{r}58.9 \\
7\end{array}$ & $\begin{array}{r}57.3 \\
9\end{array}$ & $\begin{array}{r}54.4 \\
5\end{array}$ & - & $\begin{array}{r}51 . \\
30\end{array}$ \\
\hline $\begin{array}{l}\text { Bukittinggi - } \\
\text { Padang } \\
\text { Sibuk }\end{array}$ & $\begin{array}{r}69.9 \\
0\end{array}$ & $\begin{array}{r}55.6 \\
4\end{array}$ & $\begin{array}{r}51.1 \\
2\end{array}$ & $\begin{array}{r}42 . \\
08\end{array}$ & \\
\hline $\begin{array}{l}\text { Bukittinggi - } \\
\text { Padang } \\
\text { Tidak Sibuk }\end{array}$ & $\begin{array}{r}65.3 \\
1\end{array}$ & $\begin{array}{r}60.3 \\
8\end{array}$ & $\begin{array}{r}57.5 \\
2\end{array}$ & $\begin{array}{r}51 . \\
12\end{array}$ & - \\
\hline Rata - rata & $\begin{array}{r}57.9 \\
4\end{array}$ & $\begin{array}{r}54.2 \\
5\end{array}$ & $\begin{array}{r}50.4 \\
7\end{array}$ & $\begin{array}{r}46 . \\
26\end{array}$ & $\begin{array}{r}40 . \\
40\end{array}$ \\
\hline
\end{tabular}

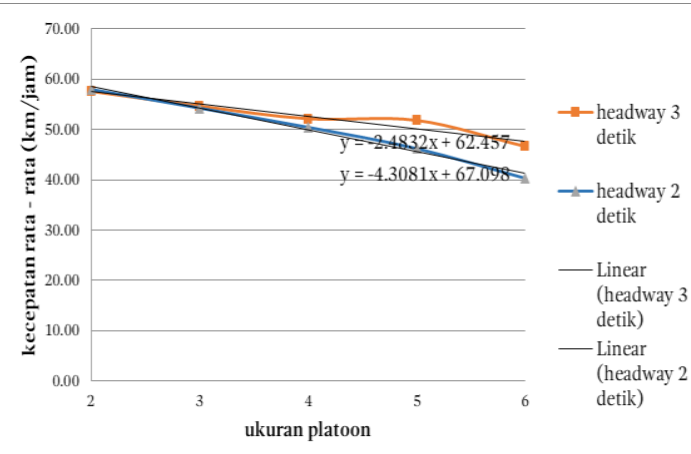

Gambar 3 Kecepatan rata-rata berdasarkan ukuran platoon

Pada gambar 3 ditampilkan rata - rata kecepatan berdasarkan ukuran platoon pada pengukuran platoon dengan headway sampai dengan 3 detik dan headway sampai dengan 2 detik, jika dilakukan regresi linear, dapat dilihat bahwa jika bahwa rata - rata kecepatan pada headway sampai dengan 3 detik mengikuti persamaan $\mathrm{y}=-2.483 \mathrm{x}+62.45$, sedangkan headway sampai dengan 2 detik mengikuti persamaan $-4.308 x+67.09$.

\section{Rekapitulasi Distribusi Kecepatan Berdasarkan Jenis Pemimpin Platoon}

Tabel 8 menampilkan rekapitulasi kecepatan rata - rata kendaraan berdasarkan jenis pemimpin platoon pada pengukuran platoon dengan headway sampai dengan 3 detik. Dari tabel dapat dilihat kecepatan rata rata platoon yang dipimpin oleh kendaraan

ringan (LV) adalah $56.22 \mathrm{~km} / \mathrm{jam}$, kendaraan berat menengah (MHV) adalah $53.43 \mathrm{~km} / \mathrm{jam}$, bus besar (LB) adalah $56.53 \mathrm{~km} / \mathrm{jam}$ dan truk besar (LT) adalah $53.57 \mathrm{~km} / \mathrm{jam}$. Tidak terlihat hubungan naik atau turunnya kecepatan seiring dengan perubahan jenis pemimpin platoon.

Tabel 8 Rekapitulasi kecepatan rata - rata kendaraan berdasarkan jenis pemimpin platoon pada pengukuran headway sampai dengan 3 detik

\begin{tabular}{|c|c|c|c|c|}
\hline \multirow[t]{2}{*}{ Hari- Arah } & \multicolumn{4}{|c|}{$\begin{array}{l}\text { Kecepatan rata -rata } \\
(\mathrm{km} / \mathrm{jam}\end{array}$} \\
\hline & $\mathrm{LV}$ & $\begin{array}{c}\mathrm{MH} \\
\mathrm{V}\end{array}$ & LB & LT \\
\hline Selasa & & & & \\
\hline $\begin{array}{l}\text { Padang - } \\
\text { Bukittinggi } \\
\text { Sibuk }\end{array}$ & $\begin{array}{r}57.8 \\
4\end{array}$ & $\begin{array}{r}53.3 \\
4\end{array}$ & - & $\begin{array}{r}58.2 \\
1\end{array}$ \\
\hline $\begin{array}{l}\text { Padang - } \\
\text { Bukittinggi } \\
\text { Tidak Sibuk }\end{array}$ & $\begin{array}{r}52.9 \\
7\end{array}$ & $\begin{array}{r}52.3 \\
2\end{array}$ & - & $\begin{array}{r}51.2 \\
8\end{array}$ \\
\hline $\begin{array}{l}\text { Bukittinggi - } \\
\text { Padang Sibuk }\end{array}$ & $\begin{array}{r}52.4 \\
2 \\
\end{array}$ & $\begin{array}{r}44.0 \\
0 \\
\end{array}$ & - & $\begin{array}{r}46.0 \\
5\end{array}$ \\
\hline $\begin{array}{l}\text { Bukittinggi - } \\
\text { Padang Tidak } \\
\text { Sibuk }\end{array}$ & $\begin{array}{r}64.4 \\
2\end{array}$ & $\begin{array}{r}56.8 \\
6\end{array}$ & - & $\begin{array}{r}56.5 \\
8\end{array}$ \\
\hline Minggu & & & & \\
\hline $\begin{array}{l}\text { Padang - } \\
\text { Bukittinggi } \\
\text { Sibuk }\end{array}$ & $\begin{array}{r}45.3 \\
7\end{array}$ & $\begin{array}{r}42.7 \\
0\end{array}$ & $\begin{array}{r}81.3 \\
9\end{array}$ & $\begin{array}{r}43.4 \\
0\end{array}$ \\
\hline $\begin{array}{l}\text { Padang - } \\
\text { Bukittinggi } \\
\text { Tidak Sibuk } \\
\end{array}$ & $\begin{array}{r}57.7 \\
3\end{array}$ & $\begin{array}{r}57.2 \\
1\end{array}$ & - & $\begin{array}{r}48.3 \\
4\end{array}$ \\
\hline $\begin{array}{l}\text { Bukittinggi - } \\
\text { Padang Sibuk }\end{array}$ & $\begin{array}{r}56.6 \\
8 \\
\end{array}$ & $\begin{array}{r}62.4 \\
9 \\
\end{array}$ & $\begin{array}{r}31.6 \\
6 \\
\end{array}$ & $\begin{array}{r}60.7 \\
8 \\
\end{array}$ \\
\hline $\begin{array}{l}\text { Bukittinggi - } \\
\text { Padang Tidak } \\
\text { Sibuk }\end{array}$ & $\begin{array}{r}60.3 \\
0\end{array}$ & $\begin{array}{r}59.4 \\
2\end{array}$ & - & $\begin{array}{r}55.8 \\
7\end{array}$ \\
\hline Rata - rata & $\begin{array}{r}56.2 \\
2 \\
\end{array}$ & $\begin{array}{r}53.4 \\
3\end{array}$ & $\begin{array}{r}56.5 \\
3\end{array}$ & $\begin{array}{r}53.5 \\
7\end{array}$ \\
\hline
\end{tabular}

Tabel 9 menampilkan rekapitulasi kecepatan rata - rata kendaraan berdasarkan ukuran platoon pada pengukuran platoon dengan headway sampai dengan 2 detik. Dari tabel dapat dilihat kecepatan rata rata platoon yang dipimpin oleh kendaraan ringan (LV) adalah $55.98 \mathrm{~km} / \mathrm{jam}$, kendaraan berat menengah (MHV) adalah $52.18 \mathrm{~km} / \mathrm{jam}$, bus besar (LB) adalah $47.15 \mathrm{~km} / \mathrm{jam}$ dan truk besar (LT) adalah $51.97 \mathrm{~km} / \mathrm{jam}$. Terjadi penurunan kecepatan seiring dengan berubahnya tipe pemimpin platoon 
Tabel 9 Rekapitulasi kecepatan rata - rata kendaraan berdasarkan jenis pemimpin platoon pada pengukuran headway sampai dengan 2 detik

\begin{tabular}{|c|c|c|c|c|}
\hline \multirow[t]{2}{*}{ Hari- Arah } & \multicolumn{4}{|c|}{ Kecepatan rata -rata $(\mathrm{km} / \mathrm{jam}$} \\
\hline & LV & $\begin{array}{c}\mathrm{MH} \\
\mathrm{V}\end{array}$ & LB & LT \\
\hline Selasa & & & & \\
\hline $\begin{array}{l}\text { Padang - } \\
\text { Bukittinggi } \\
\text { Sibuk }\end{array}$ & $\begin{array}{r}58.2 \\
2\end{array}$ & $\begin{array}{r}57.9 \\
6\end{array}$ & - & 53.04 \\
\hline $\begin{array}{l}\text { Padang - } \\
\text { Bukittinggi } \\
\text { Tidak Sibuk } \\
\end{array}$ & $\begin{array}{r}49.6 \\
6\end{array}$ & $\begin{array}{r}48.8 \\
3\end{array}$ & - & 49.39 \\
\hline $\begin{array}{l}\text { Bukittinggi - } \\
\text { Padang Sibuk }\end{array}$ & $\begin{array}{r}49.7 \\
8 \\
\end{array}$ & $\begin{array}{r}45.5 \\
5 \\
\end{array}$ & - & 41.64 \\
\hline $\begin{array}{l}\text { Bukittinggi - } \\
\text { Padang Tidak } \\
\text { Sibuk }\end{array}$ & $\begin{array}{r}58.4 \\
0\end{array}$ & $\begin{array}{r}56.5 \\
5\end{array}$ & - & 54.75 \\
\hline Minggu & & & & \\
\hline $\begin{array}{l}\text { Padang - } \\
\text { Bukittinggi } \\
\text { Sibuk }\end{array}$ & $\begin{array}{r}46.6 \\
6\end{array}$ & $\begin{array}{r}44.5 \\
6\end{array}$ & $\begin{array}{r}57.9 \\
1\end{array}$ & 39.82 \\
\hline $\begin{array}{l}\text { Padang - } \\
\text { Bukittinggi } \\
\text { Tidak Sibuk }\end{array}$ & $\begin{array}{r}58.2 \\
5\end{array}$ & $\begin{array}{r}55.0 \\
9\end{array}$ & - & 53.48 \\
\hline $\begin{array}{l}\text { Bukittinggi - } \\
\text { Padang Sibuk } \\
\end{array}$ & $\begin{array}{r}63.1 \\
3 \\
\end{array}$ & $\begin{array}{r}53.7 \\
8 \\
\end{array}$ & $\begin{array}{r}36.3 \\
9 \\
\end{array}$ & 63.66 \\
\hline $\begin{array}{l}\text { Bukittinggi - } \\
\text { Padang Tidak } \\
\text { Sibuk }\end{array}$ & $\begin{array}{r}63.7 \\
5\end{array}$ & $\begin{array}{r}55.1 \\
1\end{array}$ & - & 59.98 \\
\hline Rata - rata & $\begin{array}{r}55.9 \\
8\end{array}$ & $\begin{array}{r}52.1 \\
8\end{array}$ & $\begin{array}{r}47.1 \\
5\end{array}$ & 51.97 \\
\hline
\end{tabular}

\section{Uji Validasi}

Validasi data kecepatan dilakukan dengan membandingkan data pengukuran kecepatan hasil rekaman video dengan pengukuran kecepatan dengan alat speed gun.

Cara menghitung nilai $r$ hitung :

$$
\mathrm{r} \text { hitung }=\frac{\sum x y}{\sqrt{\sum x^{2} x \sum y^{2}}}
$$

Setelah dilakukan perhitungan nilai $\mathrm{r}$, didapat nilai $r$ hitung $=0,929$, sedangkan nilai $\mathrm{r}$ tabel adalah 0,339 , dengan membandingkan nilai $r$ hitung dengan $r$ tabel dimana $r$ hitung $>$ r tabel, maka data valid.

\section{PENUTUP}

Berdasarkan survey dan pengolahan data serta analisa dan pembahasan yang sudah dilakukan dapat disimpulkan sebagai berikut :
Ukuran platoon berpengaruh signifikan terhadap kecepatan rata - rata platoon, baik pada pengukuran platoon dengan headway sampai dengan 3 detik ataupun dengan pengukuran platoon dengan headway sampai dengan 2 detik.

Jenis pemimpin platoon berpengaruh signifikan terhadap kecepatan rata - rata platoon pada saat pengukuran platoon dengan headway sampai dengan 2 detik, tetapi tidak berpengaruh secara signifikan pada saat pengukuran platoon dengan headway sampai dengan 3 detik.

Pengukuran platoon sampai dengan 2 detik lebih berpengaruh terhadap penurunan kecepatan daripada pengukuran platoon sampai dengan 3 detik. Pada pengukuran platoon sampai dengan 2 detik terjadi penurunan kecepatan rata - rata sebesar $8.36 \%$ setiap penambahan 1 (satu) kendaraan pada platoon, sedangkan pada pengukuran platoon sampai dengan 3 detik terjadi penurunan kecepatan rata - rata sebesar $4.40 \%$.

Nilai rata - rata headway relatif sama pada pengukuran pada saat jam sibuk dan jam tidak sibuk. Secara umum headway antar kendaraan bervariasi, disebabkan kecepatan kendaraan yang tidak konstan, maka headway dipengaruhi oleh kcepatan kendaraan itu sendiri dan kendaraan didepannya.

\section{DAFTAR PUSTAKA}

Ayres, T., Li, L., Schleuning, D., \& Douglas, Y. (2001). Preferred -Headway of Highway Drivers. Intelligent Transportation System Conference (pp. 827-830). Oakland, USA: IEEE.

Departemen Perhubungan. (2009). Direktorat Jenderal Perhubungan Darat,"UndangUndang Republik Indonesia Nomor 22 tahun 2009 Tentang Lalu Lintas dan Angkutan Jalan" beserta peraturan pelaksanaannya, Departemen Perhubungan, Jakarta.

Direktorat Jenderal Bina Marga. (1997). Manual Kapasitas Jalan Raya (MKJI). Departemen PU, Jakarta.

Khisty, C. J \& Lall, B.K , (2005). DasarDasar Rekayasa Transportasi, Edisi Ke3 Jilid 1", Penerbit Erlangga, Jakarta

Mathew, J dkk. (2013). Studying Platoon Dispersion Characteristics Under 
Heterogeneous Traffic In India.

Procedia: Social and Behavioural

Sciences , 104, 422-429.

Pemerintah Indonesia, (2006), Peraturan Pemerintah Republik Indonesia Nomor 34 Tahun 2006 Tentang Jalan, Jakarta.

Pemerintah Indonesia, (2015). Keputusan Menteri Pekerjaan Umum dan Perumahan Rakyat Republik Indonesia Nomor 248/KPTS/M/2015 Tentang Penetapan Ruas Jalan dalam Jaringan Jalan Primer Menurut Fungsinya Sebagai Jalan Arteri (JAP) dan Jalan Kolektor -1 (JKP-1). Jakarta.

Purnawan \& Adilla,T. (2013). Headway Distribution of Traffict platoon in Urban Road, Case Study : Padang City, The $16^{\text {th }}$ FSTPT International Sympossium, Surakarta.

Ramezani, H, Benekohal, R.F \& Avrenli, K.A.(2008). Statistical distribution for inter platoon gaps, intra platoon headways and platoon size using field data from highway bottleneck, TRB Traffic Flow Theory Committee (TFTC) Summer Meeting and Greenshields Symposium, July 2008, USA.

Aziza, RSRA dkk. (2014). The Effect of Gross Vehicle Weight on Platoon Speed and Size Characteristics on Two Lane Road.Globalilluminators : ITMAR 2014, vol 1,708 - 714 . 